\title{
Primary-energy Based Optimization of a New Building District through Simulations on Flat, Building, Block and District Level
}

\author{
Georgios Dermentzis ${ }^{1}$, Fabian Ochs ${ }^{1}$, Alexander Thuer ${ }^{1}$ \\ ${ }^{1}$ Unit for Energy Efficient Building, University of Innsbruck, Technikerstr. 13, A-6020 Innsbruck, \\ Austria
}

\begin{abstract}
A methodology is proposed to evaluate from the energetically point of view a new building district assisting on the decision-making procedure. This residential district will be built in Innsbruck, Austria. The final and primary energy consumption with respect to space hating and domestic hot water are determined. Four major parameters are varied, which are (a) the heat generation system, which is either a heat pump (HP), district heating (DH) or a combination;

(b) central or decentral heating system, i.e. one unit per district, block, building or flat;

(c) pipe distribution system, i.e. two- or four-pipe system, and

(d) three pipe insulation levels, i.e. moderate, good or very good.

Based on final energy results in case of a HP system, a four-pipe system with one HP per building and fresh water station in each flat is suggested or a HP per building with two-pipe system and a flat-wise so-called returnflow heat pump. In case of DH, a two-pipe system with heat transfer station in each flat is recommended. The primary energy results based on Austrian standards showed that the use of HP is beneficial compared to DH. However, the results are quite sensitive to the primary energy conversion factors, especially for the $\mathrm{DH}$, which is specific to each case.
\end{abstract}

\section{Introduction}

The building sector plays an important role in energy consumption. Many simulation studies for energy optimization of one building can be found in the literature (W Feist and Schnieders 2009; Dermentzis et al. 2019). However, in recent years, the focus on energy optimization of districts, cities or regions increases and many tools were developed (Dermentzis et al. 2017).

A new district will be constructed in Innsbruck, Austria. The goal is to build the district with the lowest environmental impact without sacrificing the requirement for affordable living. Thus, the questions are the following:

- Which type of heat generation system?

- Which pipe distribution system and emission system?

- How many heating systems? Decentral, i.e. one per flat, semi-central, i.e. one per building or per block, or central one per district.
Truong and Gustavsson (2019) compared electric heat pumps to district heating with respect to primary energy for a new residential area in Sweden. They showed that using the current energy mix of district heating and electricity production, district heating is more efficient, however, with high possibility to change this trend in future. Wang (2018) compared individual heat pumps, district heating networks and gas boilers for the UK market, resulted that gas boilers have the lower cost, and air source heat pumps are economic compared to ground source heat pump and district heating. With respect to heat distribution system, Vaillant Rebollar et al. (2017) developed a simplified calculation method to investigate the heat losses of two-pipe heat-distribution system with substation in each flat. It was found that a well-insulated and short distribution system that provides high amount of heat was the most efficient. Ochs el al. (2014) suggested a four-pipe distribution system with floor heating and a heat exchanger for the domestic hot water in each flat, in combination with a ground-water heat pump.

In this study, the energy optimization for this new district is presented. The investigated variables are: a) the type of heat generation system i.e. heat pump, district heating or both, b) the pipe distribution system (with the corresponding water temperature), c) the insulation level of the pipes, and d) the number of heat generation systems i.e. one per flat, building, block or district. Due to the very compact and dense housing situation (high-rise buildings), the use of solar energy would have an insignificant contribution and thus, it was disregarded in this study. The fixed boundary conditions are the following: the climate of Innsbruck, the buildings energy standards that are Passive House, the use of floor heating, and the use of the primary energy factors for electricity and local district heating (composed of biomass, waste heat, gas) according to Austrian standards. The primary energy evaluation can be also performed using monthly factors instead of annual (Ochs and Dermentzis 2018) to account for seasonal effect in the energy mix both for electricity and district heating.

The contribution of this paper to the literature is to support decision-making with respect to energy performance of residential districts, regarding type and number of heat generation system, and type and insulation level of heat distribution system. The aim is to evaluate all the combinations of the aforementioned variables through simulations and to conclude about the most energy 
efficient solutions. The results are considered for decision-making and can be the basis for future constructions, too.

\section{Case study}

\section{New building district - "Campagne Areal"}

A new district is going to be built in Innsbruck, Austria. It will consist of 1128 flats in $78027 \mathrm{~m}^{2}$, distributed in 16 buildings and 4 blocks (Figure 1), and sport facilities (including approximately 41 flats). All buildings will be constructed according to Passive House standards (iPHA). An energetic optimization is performed within the Austrian research project Campagne. The energy analysis in this study focuses on the residential part, which belongs to two social housing companies in Innsbruck (Immobiliengesellschaft Innsbruck (IIG) and Neue Heimat Tirol (NHT)). In this climate, with a negligible cooling load in residential buildings, the focus is on heating and domestic hot water (DHW) supply. The construction is divided in four phases; one block (consisting of four buildings) per phase, starting with block 1 (see Figure 2). In this district, the buildings will be high-rise and dense, i.e. with an average of 71 apartments per building.

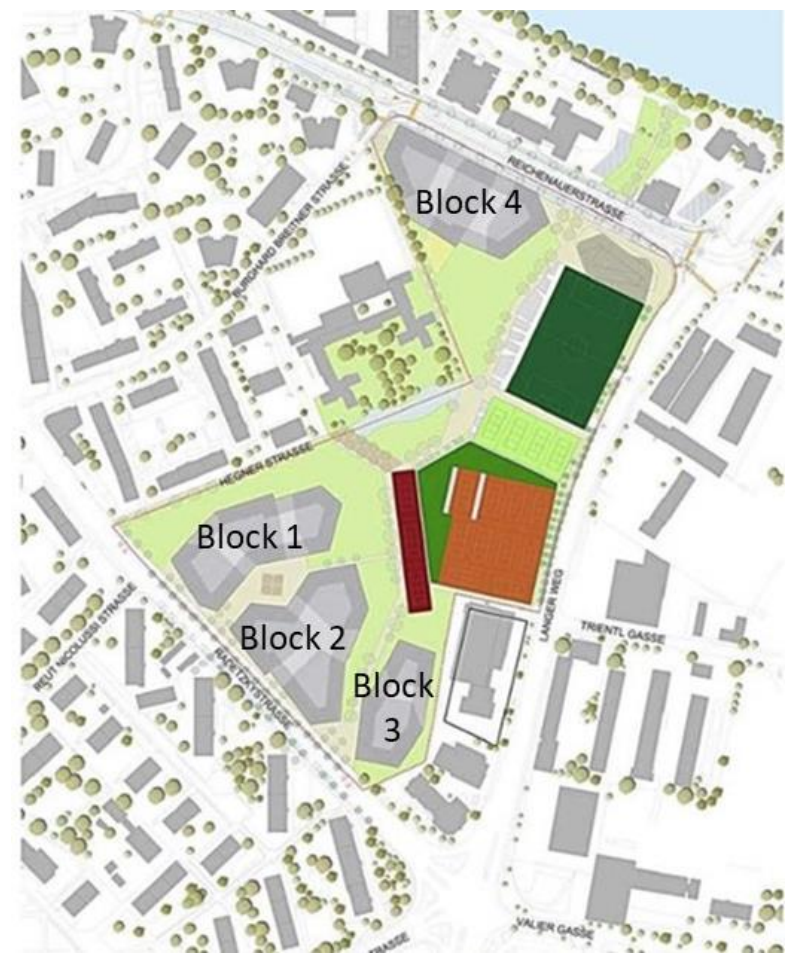

Figure 1: Sketch of the new district Campagne Areal in Innsbruck (ibkinfo.at).

\section{Investigated systems}

In the early design stages, it was decided to investigate whether district heating (DH) and/or heat pumps (HP) should supply the required heat. Even though, photovoltaics will be installed, they are not considered in the investigations. They can contribute only to cover part of the electricity for the appliances, because of the highdense occupied buildings (small available roof area). Ground water is available as source for the heat pumps. However, the volume flow of ground water and the annual amount of extracted energy are restricted and thus, the potential of ground water is limited. A ground-water volume flow of $57 \mathrm{l} / \mathrm{s}$ is guaranteed with a maximum potential of $100 \mathrm{l} / \mathrm{s}$. The guaranteed volume flow corresponds to $1.5 \mathrm{MW}$ heating capacity of the heat pump assuming a coefficient of performance (COP) of 5.5 (e.g. for space heating). This could be high enough to supply the space heating of the district but hardly possible to supply also the DHW. Theoretically, additional air-tobrine cooler could be used in parallel to ground water source to enhance the heating capacity of the HP (for high loads, but this option was not further investigated.

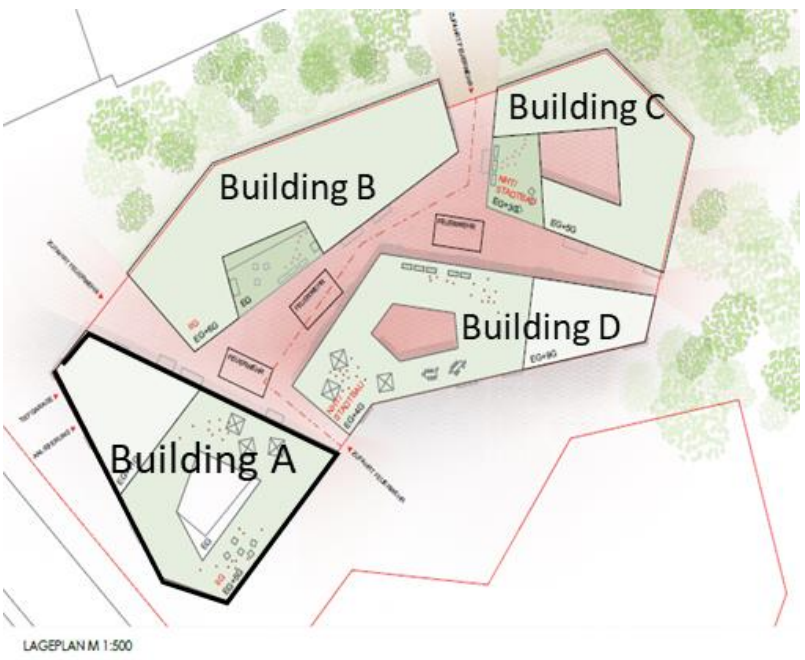

Figure 2: Sketch of the block 1 in Campagne Areal, Innsbruck (ibkinfo.at).

The heat supply system (DH and/or HP) can be located (a) centrally for the whole district or (b) per block or (c) per building. In addition, a heating system per flat can be installed for the DHW supply: return-flow heat pump (RFHP) or electric boiler. Table 1 shows the five investigated concepts with respect to pipe distribution and the corresponding flow temperature for heating and DHW. The owners were in favour of floor heating as heat emission system, resulting in low flow temperature.

Table 1: Investigated heat distribution (piping) systems and the corresponding design flow temperatures

\begin{tabular}{|c|c|c|c|}
\hline $\begin{array}{l}\text { System } \\
\text { Abbre- } \\
\text { viation }\end{array}$ & System description & $\begin{array}{c}\vartheta \text { flow } \\
\text { Heating } \\
{\left[{ }^{\circ} \mathrm{C}\right]}\end{array}$ & $\begin{array}{c}\vartheta \text { flow } \\
\text { DHW } \\
{\left[{ }^{\circ} \mathrm{C}\right]}\end{array}$ \\
\hline $4 \mathrm{P}-\mathrm{C}$ & $\begin{array}{l}\text { four-pipe system with } \\
\text { circulation }\end{array}$ & 35 & 60 \\
\hline 4P-FWS & $\begin{array}{l}\text { four-pipe system with } \\
\text { fresh water station }\end{array}$ & 35 & 52 \\
\hline 2P-FWS & $\begin{array}{l}\text { two-pipe system with } \\
\text { fresh water station }\end{array}$ & 52 & $(52)$ \\
\hline $\begin{array}{c}2 \mathrm{P}- \\
\text { RFHP }\end{array}$ & $\begin{array}{l}\text { two-pipe system with } \\
\text { return-flow heat pump }\end{array}$ & 35 & (55) \\
\hline 2P-EB & $\begin{array}{l}\text { two-pipe system with e- } \\
\text { boilers }\end{array}$ & 35 & $(55)$ \\
\hline
\end{tabular}


Remark: In case of four-pipe system, separate storages are assumed for heating and DHW. In case of two-pipe system, one storage per heat pump (one central) or one per flat) is used.

All the varied parameters in this study are presented in Table 2, leading to 90 combinations. Furthermore, as an option, shower-drain water heat recovery was investigated, which has in particular in case of the decentral DHW preparation options a potential to reduce significantly the DHW demand.

Table 2: Varied parameters of the investigated heat generation, and distribution options

\begin{tabular}{|c|c|c|c|}
\hline $\begin{array}{c}\text { Heat } \\
\text { supply } \\
\text { system }\end{array}$ & $\begin{array}{c}\text { Heating } \\
\text { system per }\end{array}$ & $\begin{array}{c}\text { Pipe } \\
\text { distribution } \\
\text { system }\end{array}$ & $\begin{array}{c}\text { Insulation } \\
\text { level }\end{array}$ \\
\hline $\begin{array}{c}\text { heat pump } \\
\text { (HP) }\end{array}$ & building & 4P-C & moderate \\
\hline $\begin{array}{c}\text { district } \\
\text { heating } \\
\text { (DH) }\end{array}$ & block & 4P-FWS & good \\
\hline $\begin{array}{c}\text { heat pump } \\
\text { \& district } \\
\text { heating }\end{array}$ & district & 2P-FWS & very good \\
\hline & & 2P-RFHP & \\
\hline & & 2P-EB & \\
\hline
\end{tabular}

Remark: A heating system per district corresponds to one technical room in the whole district with a HP and/or a heat exchanger for DH (see Figure 3). A heating system per building corresponds to e.g. 16 HPs or 16 heat exchangers for the connection to $\mathrm{DH}$.

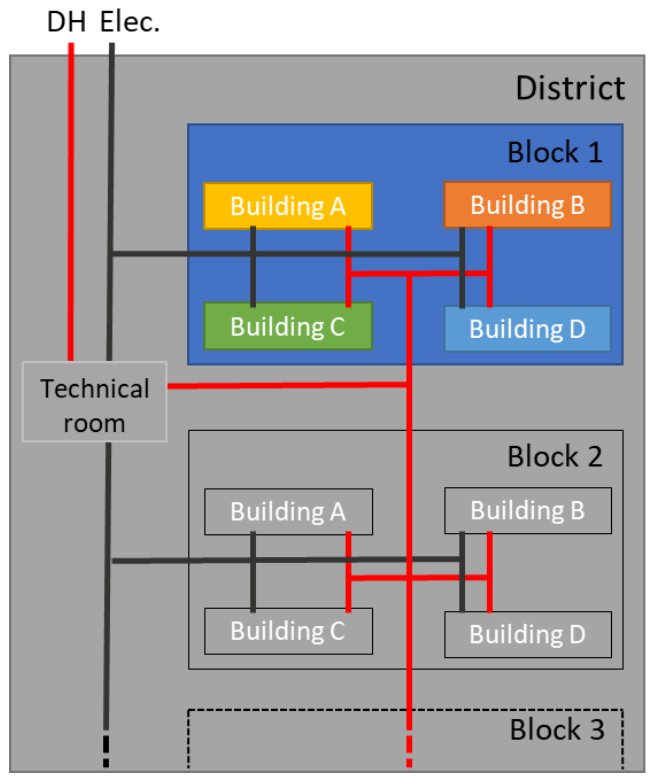

Figure 3: Simplified scheme of the district with the levels building, block and district

\section{Methodology}

\section{Simulation level}

The energy performance of the district can be evaluated by performing simulations in different levels, as shown in Figure 4 . The most detailed approach would be to model every flat as a thermal zone including the DHW consumption and simulate the whole district. However, this would be time and computational consuming, and there would be a high uncertainty of the input data (e.g. the last block will be constructed in some years later (here eight), thus, the possibility of new decisions is high). Another option would be to simulate a representative flat. The approach that is used in this study was to design and model one building in detail and then expand the results to the whole district.

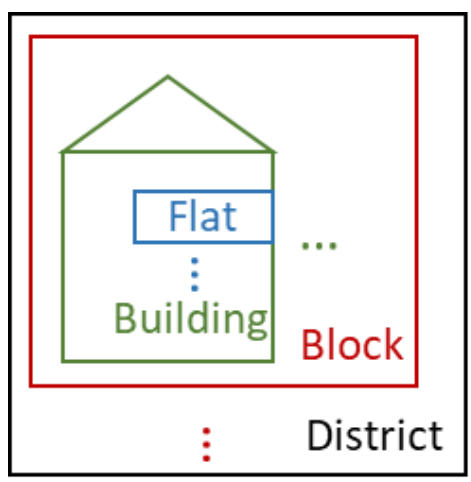

Figure 4: Various possible simulations levels.

To summarize, the methodology used is the following. Heating and distribution system are simulated for a reference building (including decentralised systems for DHW supply). The specific consumption per heated area used to calculate the consumption of the district and in addition, the thermal losses of the pipes from district border to each block and each building are added to the consumption.

Since now, more design details are available for block 1, the building A from this block is chosen as a reference building (see Figure 5). It consists of 89 flats with $7600 \mathrm{~m}^{2}$. It has partly 6 and partly 11 floors. An engineering office, which is specialised in dimensioning of heating, ventilation and air-conditioning (HVAC) systems, designed in detail the distribution pipes within the reference building for the five different concepts (see Table 1). The local utility company planned the dimensioning of the pipes for the heat distribution within the district (district border to each building) depending on the heat generation system (HP and DH).

\section{Simulation tool}

A tool is developed in Matlab (MathWorks 2016) to calculate the thermal losses and the required final and primary energy for every system with hourly resolution. 


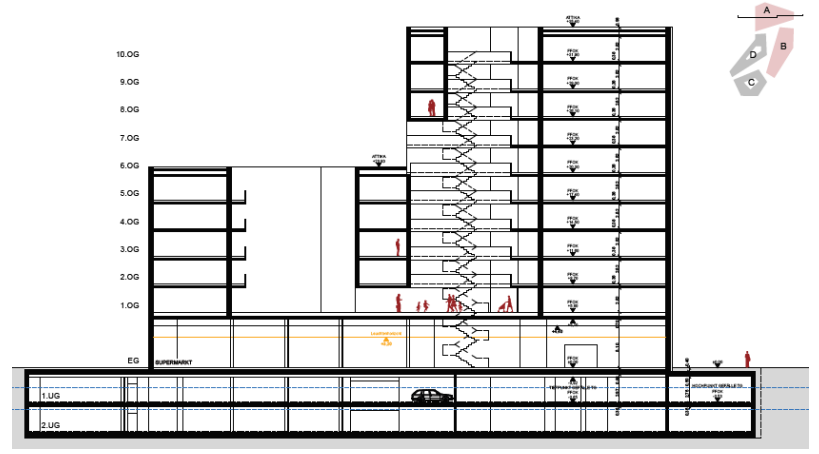

Figure 5: Building A of block 1 (source: "bogenfeld ARCHITEKTUR")

The reference building was simulated in Matlab/Simulink using the CarnotUIBK toolbox (Siegele, Leonardi, and Ochs 2019), automatically taking the required input data from an available draft version of PHPP (Wolfgang Feist 1998). As a next step, the hourly heating load was inserted in the developed tool. The space heating demand was $14.5 \mathrm{kWh} /\left(\mathrm{m}^{2} \cdot \mathrm{yr}\right)$ and the load duration curve is presented in Figure 6. The DHW profile of tapping cycle M, which is described in EN 16147 (2017), is used. The designed average number of persons per flat is 2.1 , resulting in $3.1 \mathrm{kWh} /$ day for each flat (corresponding to $5.8 \mathrm{kWh} /$ day for four persons/flat). The peak load for the DHW is calculated assuming a simultaneity factor of 0.2. In order to fulfil the energy balance, the reduced energy in the peak power (due to simultaneity factor) is added in the hour before or after the peak hour.

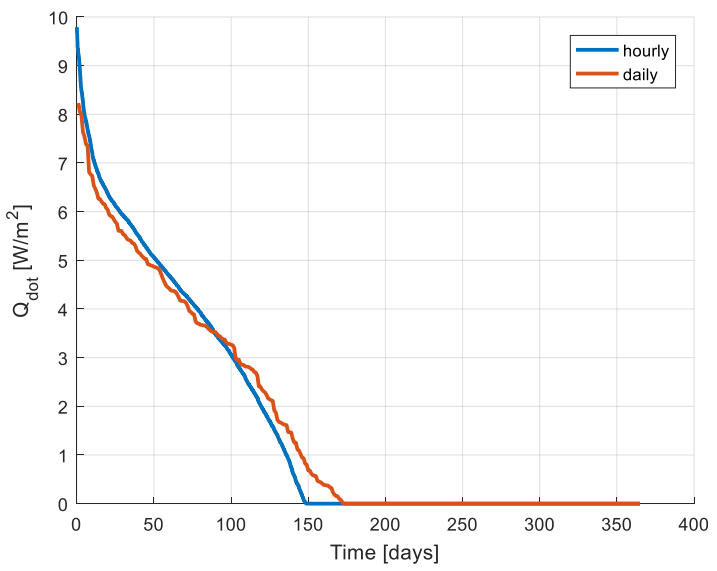

Figure 6: Load Duration Curve of the reference building in hourly and daily average values

The heat pump is modelled based on Carnot cycle, using a Carnot performance factor $\eta_{\mathrm{C}}$ (see eq. 1), which is assumed to be dependent on the design flow temperature. The higher the flow temperature, the slightly lower the Carnot performance factor is. The inlet source groundwater temperature is set to $10^{\circ} \mathrm{C}$. The COP for sink temperature of $35^{\circ} \mathrm{C}$ and $55^{\circ} \mathrm{C}$ is 5.5 and 2.9 , respectively.

$$
C O P=\eta_{C} \cdot \frac{T_{\text {sink }}}{\left(T_{\text {sink }}-T_{\text {source }}\right)}
$$

The pipe distribution losses in the building are calculated as described in eq. 2-4 based on the method used in PHPP (Wolfgang Feist 1998), using the same assumptions for the thermal bridges due to mounting and pipe suspensions. It is distinguished in non-useful losses and useful losses. Non-useful losses are the losses in the nonheating season and the losses from the pipes that are located outside the thermal envelope of the building. As useful are considered the losses during the heating season from the pipes and storages that are located inside the thermal envelope. These reduce the space heating need and they are accounted in such a way.

$$
\begin{gathered}
\dot{Q}_{\text {loss }}=\Psi \cdot l \cdot\left(T_{w}-T_{a m b}\right) \\
T_{w}=\frac{\left(T_{\text {in }}-T_{\text {out }}\right)}{2} \\
\Psi=\frac{2 \cdot \pi}{\left[\frac{1}{\lambda_{p}} \cdot \ln \left(\frac{r_{p}}{r_{i}}\right)+\frac{1}{\lambda_{\text {ins }}} \cdot \ln \left(\frac{r_{e}}{r_{p}}\right)+\frac{1}{\left(r_{e} \cdot h_{e}\right)}\right]}
\end{gathered}
$$

The eq. 5-7 describe how the distribution losses from the underground pipes within the district are calculated as proposed by Nussbaumer et al. (2017). The border of the district is used also as a border for the thermal losses of the district heating system within Campagne Areal. Thus, the flow and return temperature in case of $\mathrm{DH}$ was dependant on location of the connection to the DH. For example, if a connection to DH per block is assumed, then the flow temperature in the pipe from Campagne Areal border to the blocks is $90{ }^{\circ} \mathrm{C}$ and from the block to the buildings e.g. $65^{\circ} \mathrm{C}$ or $55^{\circ} \mathrm{C}$ depending on the distribution system.

$$
\dot{Q}_{\text {loss }}=U \cdot A_{\text {surf }} \cdot\left(T_{\text {pipe }}-T_{\text {gr }}\right)
$$

$$
\begin{gathered}
U=\frac{1}{\frac{r_{p}}{\lambda_{\text {ins }}} \cdot \ln \left(\frac{r_{e}}{r_{p}}\right)+\frac{r_{p}}{\lambda_{g r}} \cdot \ln \left(\frac{4 \cdot\left(d+r_{e}\right)}{r_{e}}\right)+\frac{r_{p}}{\lambda_{g r}} \cdot \ln \left\{\left[\left(\frac{2 \cdot\left(d+r_{e}\right)}{s+2 \cdot r_{e}}\right)^{2}+1\right]^{0.5}\right\}} \\
A_{\text {surf }}=2 \cdot \pi \cdot 2 \cdot r_{p} \cdot l
\end{gathered}
$$

\section{Results}

\section{Thermal losses}

First, the thermal losses for the five distribution systems are calculated excluding the heat supply system and any thermal losses in the district (i.e. assuming a construction of only one building). Figure 7 presents the non-useful thermal losses for three pipe-insulation levels.

The systems with the lowest losses are those with the fresh water station (4P-FWS and 2P-FWS) in case of "very good" insulation level, and the flat-wise systems (2PRFHP and 2P-EB) in case of "moderate" insulation.

The highest losses are observed in $4 \mathrm{P}-\mathrm{C}$ system due to high temperature for the DHW and higher pipe length compared to the other system. It has to be mentioned that more rising pipes are required for a circulation system than for 4P-FWS system to avoid pressure losses due to the relative high number of floors. If the same pipe length as e.g. the $4 \mathrm{P}-\mathrm{FWS}$ is used, the thermal losses decrease by $29 \%$.

Figure 8 shows the thermal losses of the whole district (including the non-useful losses inside the building and the pipe losses in the district) for both types of heating systems in three configurations (one unit per building, block or district). The trends with respect to the insulation 
level are the same as those in Figure 7; therefore, the results only for the "good" insulation level are presented.

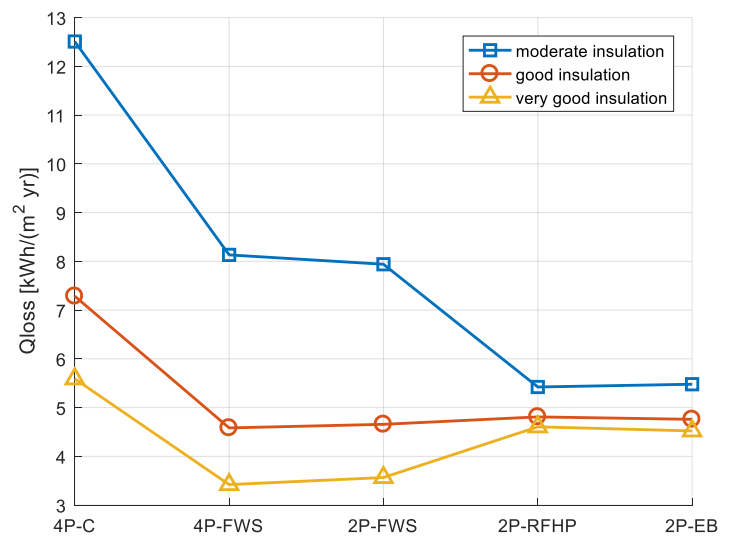

Figure 7: Non-useful thermal losses in building level for five distribution systems and three insulation levels.

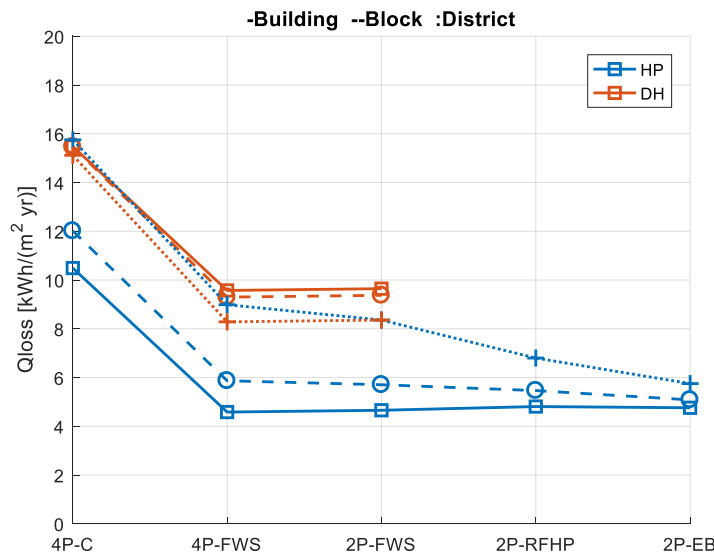

Figure 8: Non-useful thermal losses in building and district level in "good insulation" level, using HP or DH per building (continues line), block (dash line) or district (dot line) for five distribution systems.

The use of HP results in significantly lower losses compared to DH, especially in case of one HP per building. As for the distribution system, excluding the 4P$\mathrm{C}$, the rest are in the same order of magnitude.

\section{Final energy}

Figure 9 presents the required final energy, which in case of HP is electricity, as a function of the distribution system having as parameters the insulation level and the district-central or decentral heating system. The 4P-FWS is in favour of "good" insulation and is the most efficient system. The 2P-RFHP is hardly influenced by the insulation level (due to low flow and return temperatures) and has the lowest consumption in case of "moderate" insulation. The 2P-FWS is the third option with about $1.5 \mathrm{kWh} /\left(\mathrm{m}^{2} \cdot \mathrm{yr}\right)$ to $2 \mathrm{kWh} /\left(\mathrm{m}^{2} \cdot \mathrm{yr}\right)$ higher consumption than the 2P-RFHP. The other two options (4P-C and 2P$\mathrm{EB})$ result in significantly higher consumption. The use of one HP per building (continuous line in Figure 9) reduces the final energy compared to one central HP by $2 \mathrm{kWh} /\left(\mathrm{m}^{2} \cdot \mathrm{yr}\right)$ for the FWS systems (dot line in Figure 9), and by $0.8 \mathrm{kWh} /\left(\mathrm{m}^{2} \cdot \mathrm{yr}\right)$ for the $2 \mathrm{P}-\mathrm{RFHP}$.
It is worth to mention that a difference of specific FE of $1 \mathrm{kWh} /\left(\mathrm{m}^{2} \cdot \mathrm{yr}\right)$ corresponds to a quite high absolute difference in energy consumption (due to the large area of the district): $78 \mathrm{MWh} / \mathrm{yr}$, which is enough to cover annual space heating of a Passive House with a total area of $5202 \mathrm{~m}^{2}$.

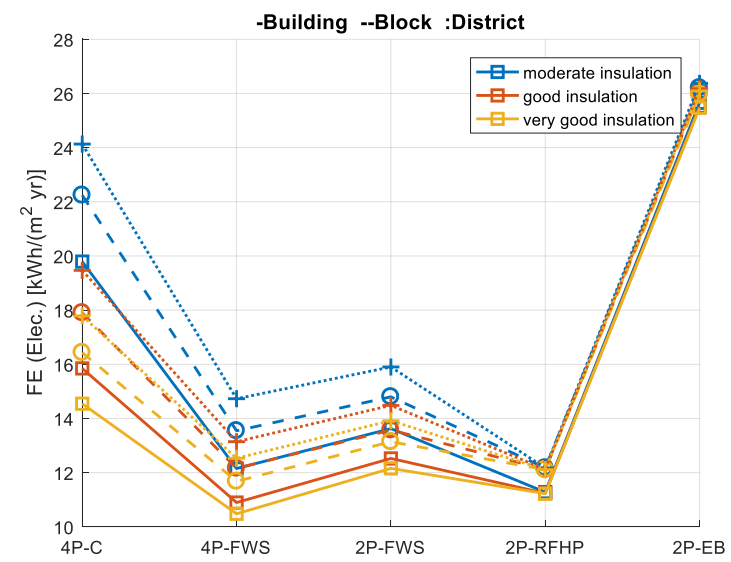

Figure 9: Final energy (electricity) of the district when one HP installed per building (continuous line), block (dash line) or district (dot line) for three insulation levels and five distribution systems

Figure 10 is similar to Figure 9 but shows the final energy for the case of $\mathrm{DH}$, which is heat instead of electricity. The use of 4P-FWS and 2P-FWS leads to similar performance, while the $4 \mathrm{P}-\mathrm{C}$ is significantly higher.

In case of $\mathrm{DH}$, the option of a connection in each building increases the final energy up to $1.5 \mathrm{kWh} /\left(\mathrm{m}^{2} \cdot \mathrm{yr}\right)$ (depending on the insulation level) compared to one central solution for the whole district, which is in contrast to the case of HP. This occurs since in the case of one central solution, the flow temperature in the distribution pipes within the district is e.g. $55^{\circ} \mathrm{C}$ (for $\mathrm{FWS}$ ), while it is $90{ }^{\circ} \mathrm{C}$ in case of a connection to $\mathrm{DH}$ in each building. Furthermore, the insulation level has higher impact on the final energy compared to the choice of central or decentral heating system in the district.

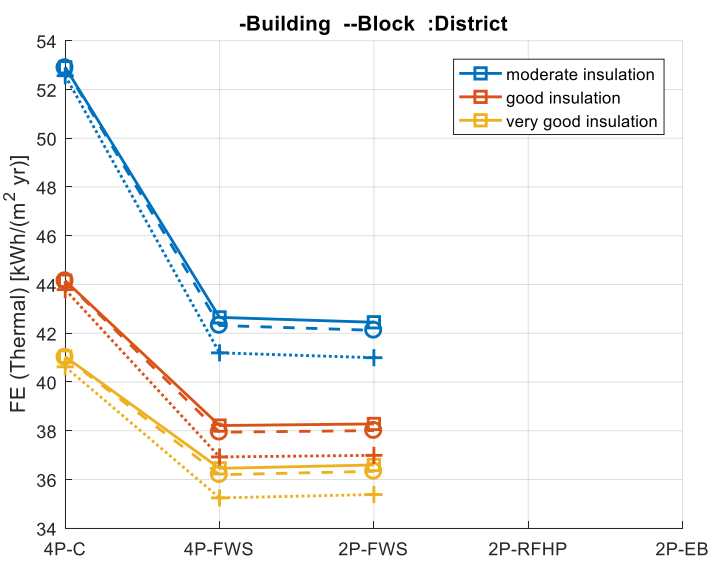

Figure 10: Final energy (heat) of district in case of DH connection per building (continuous line), block (dash line) or district (dot line) for three insulation levels and five distribution systems 
The combination of 2-RFHP or 2P-EB with DH are not investigated further. These two options are beneficial in case of HP because of low distribution temperature that leads to significantly high performance of the HP. Contrariwise, in case of $\mathrm{DH}$, the potential benefit of using high shares of waste heat in summer would remain unused in case of 2-RFHP or 2P-EB.

\section{Primary energy}

In order to compare the two heat generation systems (HP with electric energy and DH with thermal energy), conversion factors of final energy to primary energy are required. The annual factors that are defined in the Austrian standards (Österreichisches Institut für Bautechnik 2015) are used in the primary energy calculation. The annual conversion factors for electricity is 1.91 and for $\mathrm{DH} 0.94$.

One additional option is included in this section, which is the combination of HP and DH with a four-pipe system. In that configuration, HP covers the space heating in low flow temperature $\left(35^{\circ} \mathrm{C}\right)$ and $\mathrm{DH}$ covers the DHW demand. Two systems are fully separated to avoid complexity.

The required primary energy is demonstrated in Figure 11, Figure 12 and Figure 13 correspondingly to each insulation level, having as parameters the heat supply system (different colours) and the option of central or decentral heating system in the district (different markers and line style).

The results indicate that the installation of a HP per building with $4 \mathrm{P}-\mathrm{FWS}$ is the most efficient system with good or "very good" insulation level and with a 2P-RFHP with "moderate" insulation level. The use of HP is beneficial compared to DH except for the 2P-EB system. The combination of DH \& HP is the second option and the DH results in the highest primary energy. The insulation level has the same impact on primary energy as with the choice of central or decentral heating system in the district in case of HP and higher influence in case of DH.

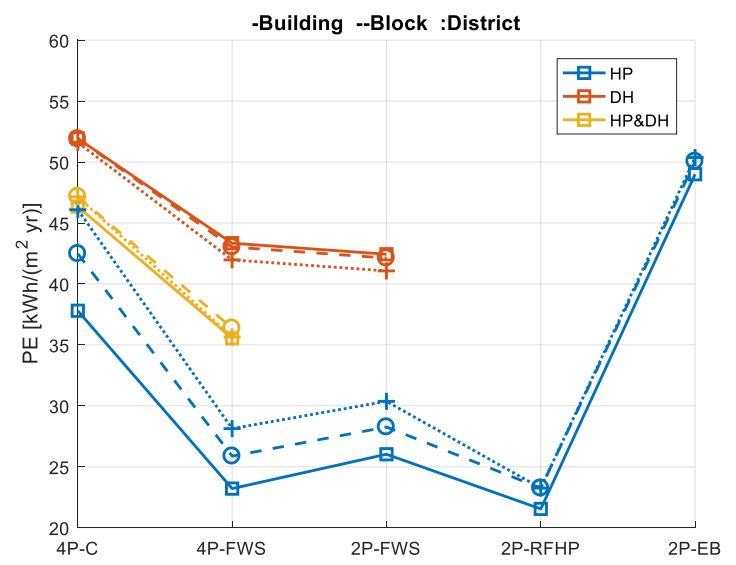

Figure 11: Primary energy for three heat-generation systems (HP, DH and combined - HP for heating and DH for DHW) installed per building (continues line),

block (dash line) or district (dot line) and for five distribution systems with "moderate insulation" level

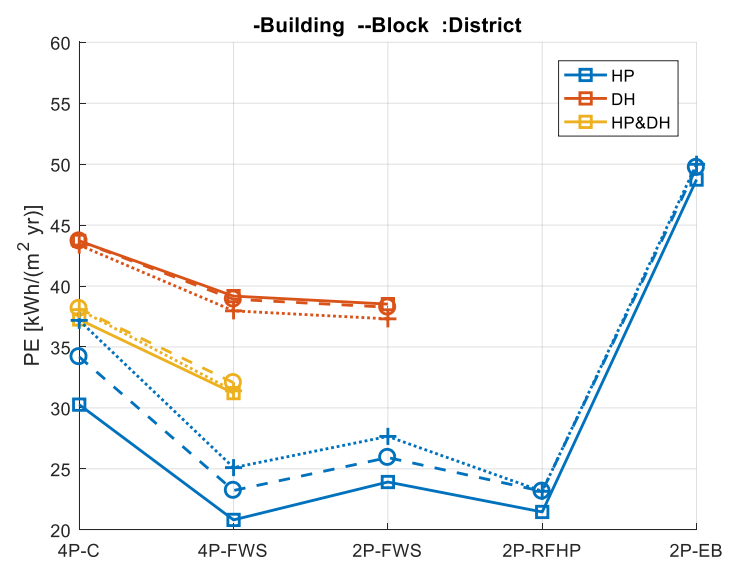

Figure 12: Primary energy for three heat-generation systems (HP, DH and combined - HP for heating and DH for DHW) installed per building (continues line), block (dash line) or district (dot line) and for five distribution systems with "good insulation" level

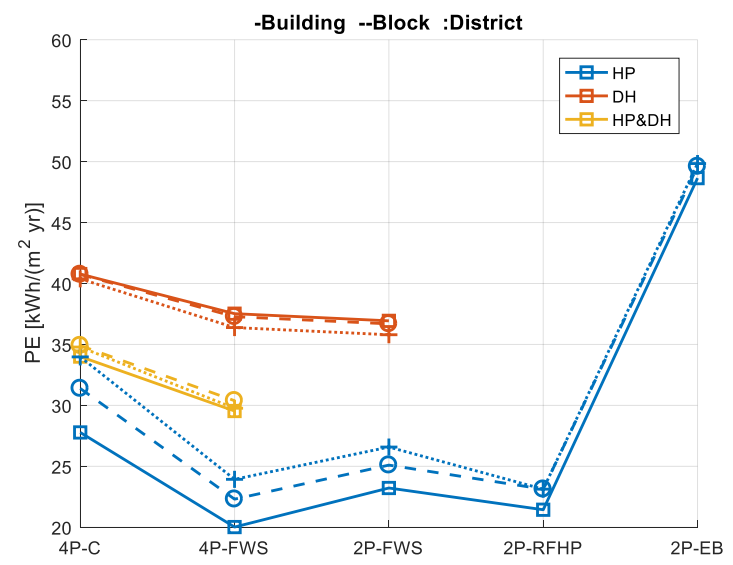

Figure 13: Primary energy for three heat-generation systems (HP, DH and combined - HP for heating and DH for DHW) installed per building (continues line), block (dash line) or district (dot line) and for five distribution systems with "very good insulation" level

To summarize, in case of HP is beneficial to use one per building with a 4P-FWS or 2P-RFHP. In case of HP \& $\mathrm{DH}$, the best option is a 4P-FWS and the choice of insulation level influences significantly the primary energy, while the decision for a central or decentral heating system in the district plays a minor role. In case of DH, a 2P-FWS is the optimal solution and same as in the case of HP \& DH the choice of insulation level is important, while the choice of central or decentral solution is not.

\section{Discussion}

A methodology for the evaluation of various heating and distribution systems is proposed in this study. It is based on detailed modelling and simulation of a reference building and expansion of the results based on the heated area. As a next step, the pipe losses within the district are also incorporated in the energy balance. This approach is valid considering that every building would be 
constructed with the same energy standards - in this case Passive House standard.

The results with respect to thermal losses or final energy showed that a 4P-FWS or 2P-RFHP are beneficial for a $\mathrm{HP}$ and the 2P-FWS for DH. A central connection to the $\mathrm{DH}$ is more efficient than a connection in each building, while the opposite applies for the HP i.e. a HP per building leads to lower consumption than one HP per district. From the primary energy point of view, HP has the lowest primary energy compared to $\mathrm{DH}$ or even a combination of both.

However, the conversion factors for the primary energy calculation play a very significant role. In this study, annual conversion factors according to the national building code (Österreichisches Institut für Bautechnik 2015) are considered. Instead, in order to account for different energy carrier in the electricity mix as well as in the district heating, e.g. monthly values could be used (Ochs 2018; Ochs and Dermentzis 2018). This may have a significant influence on the results. In addition, the estimation of the conversion factors is crucial especially for the DH, which is very case specific. For example, Streicher (2018) evaluated the DH in the city of Innsbruck and compared it to DH in other Austrian cities.

The present results can be used for decision-making procedure for the district Campagne Areal in Innsbruck. In this case, the potential of ground water extraction is limited and therefore, an only HP solution is not possible at the Campagne Areal without exploiting a further source for the HP such as air. However, the use of air as source corresponds to lower performance due to low ambient temperature in winter. Thus, an option with HP \& DH seems the most appropriate from the energy point of view. Moreover, usually DH has a high share of waste heat in summer, but a high fossil share in winter when the load is high. In the combined option, the waste heat in summer would be used for DHW supply and the required heat from the DH would be low in winter, since the HP would supply the space heating. Consequently, an integration of HPs in DH systems is an option to increase the fraction of renewables in the DH system. However, for the best performance, HPs should be integrated in a semi-central way close to the buildings and deliver energy at low temperature level.

From the economic point of view, a two-pipe system is slightly preferable e.g. with DH compared to four-pipe systems. In addition, one big HP is more economic than 16 HPs (one per building), while this has less influence in case of DH.

$\mathrm{DH}$ has some advantages compared to HP, since it is guarantied to provide enough power at the required temperature level $24 \mathrm{~h} /$ day all over the year, while in case of a HP an additional back-up solution might be required. From the maintenance point of view, DH requires less effort and human resources, and it possibly has higher lifetime compared to HP.

\section{Conclusions}

A new district, which is going to be built in Innsbruck, is evaluated by means of building and HVAC simulation with respect to final and primary energy for various distribution and heating supply system combinations, installed either in each flat (decentral), building, block (semi-central) or district (central). The methodology used is based on simulating one reference building and adding the thermal losses of the pies that are between the district border and each building.

In this study, the results show that a heat pump (HP) system has the lowest consumption of primary energy compared to district heating (DH) or HP\&DH. If HP is used as supply system, a well-insulated four-pipe distribution system combined with fresh-water station in each flat is the best option and it is preferred to install a $\mathrm{HP}$ per building rather than per district. In case of $\mathrm{DH}$, a well-insulated two-pipe system with fresh-water station is suggested, while the decision for one connection to $\mathrm{DH}$ per building or per district is not crucial.

As future work, it is suggested to use also monthly primary energy factors in order to include the influence of seasonal variations and to vary the conversion factors with respect to the specific DH of the city of Innsbruck.

\section{Acknowledgements}

This publication is part of the Austrian research project "Smart City Campagne-Areal Innsbruck". This project is financed by the Austrian "Klima- und Energiefonds" and performed in the frame of the program "Smart Cities Demo 2016". The authors highly appreciate the support and cooperation of the companies IIG, NHT, IKB and Klimatherm.

\section{Nomenclature}

\begin{tabular}{|c|c|}
\hline \multicolumn{2}{|c|}{ Abbreviations } \\
\hline $2 \mathrm{P}$ & Two-pipe system \\
\hline $4 \mathrm{P}$ & Four-pipe system \\
\hline $\mathrm{COP}$ & Coefficient of performance \\
\hline $\mathrm{DH}$ & District heating \\
\hline DHW & Domestic hot water \\
\hline EB & Electric boiler \\
\hline FWS & Fresh water station system \\
\hline HP & Heat pump \\
\hline HVAC & Heating, ventilation and air-conditioning \\
\hline RFHP & $\begin{array}{l}\text { Return-flow heat pump (a water-to-water heat } \\
\text { pump with source the return flow of the floor } \\
\text { heating and supply hot water to a storage } \\
\text { representing a flat-wise solution for DHW) }\end{array}$ \\
\hline \multicolumn{2}{|c|}{ Symbols } \\
\hline$\eta_{C}$ & Carnot performance factor \\
\hline$\lambda_{g r}$ & Thermal conductivity of the ground in $[\mathrm{W} /(\mathrm{m} \cdot \mathrm{K})]$ \\
\hline$\lambda_{\text {ins }}$ & $\begin{array}{l}\text { Thermal conductivity of insulation material in } \\
{[\mathrm{W} /(\mathrm{m} \cdot \mathrm{K})]}\end{array}$ \\
\hline$\lambda_{p}$ & Thermal conductivity of the pipe in $[\mathrm{W} /(\mathrm{m} \cdot \mathrm{K})]$ \\
\hline$\Psi$ & Heating loss coefficient per $\mathrm{m}$ of pipe $[\mathrm{W} /(\mathrm{m} \mathrm{K})]$ \\
\hline$A_{\text {surf }}$ & $\begin{array}{l}\text { Surface area of the pipe (including insulation) in } \\
{\left[\mathrm{m}^{2}\right]}\end{array}$ \\
\hline
\end{tabular}




\begin{tabular}{|ll|}
\hline$d$ & Depth of the pipes in the ground in [m] \\
$h_{e}$ & External heat transfer coefficient in $\left[\mathrm{W} /\left(\mathrm{m}^{2} \cdot \mathrm{K}\right)\right]$ \\
$l$ & Length of the pipe in [m] \\
$\dot{Q}_{\text {loss }}$ & Thermal losses in [W] \\
$r_{e}$ & External radius of the pipe including insulation in \\
$r_{i}$ & [m] \\
$r_{p}$ & Internal radius of the pipe in [m] \\
$s$ & Radius of the pipe excluding insulation in $[\mathrm{m}]$ \\
$T_{\text {amb }}$ & Ambient air temperature of the pipe in $[\mathrm{K}]$ \\
$T_{g r}$ & Ground temperature in $[\mathrm{K}]$ \\
$T_{\text {in }}$ & Inlet water temperature in the pipe in [K] \\
$T_{\text {out }}$ & Outlet water temperature in the pipe in $[\mathrm{K}]$ \\
$T_{\text {sink }}$ & Outlet water in the sink side of the heat pump in \\
& [K] \\
$T_{\text {source }}$ & Inlet water in the source side of the heat pump in \\
$T_{w}$ & [K] \\
$U$ & Average water temperature in the pipe in $[\mathrm{K}]$
\end{tabular}

\section{References}

Dermentzis, Georgios, Fabian Ochs, Marcus Gustafsson, Toni Calabrese, Dietmar Siegele, Wolfgang Feist, Chiara Dipasquale, Roberto Fedrizzi, and Chris Bales. 2019. "A Comprehensive Evaluation of a Monthly-Based Energy Auditing Tool through Dynamic Simulations, and Monitoring in a Renovation Case Study." Energy and Buildings 183. Elsevier B.V.: 713-726. doi:10.1016/j.enbuild.2018.11.046.

Dermentzis, Georgios, Jürgen Schnieders, Rainer Pfluger, Domink Pfeifer, Wolfgang Feist, and Fabian Ochs. 2017. "An Overview of Energy District Tools in Europe and the Importance of an Equivalent Heating Reference Temperature for District Simulations." Bauphysik 39 (5): 316-329. doi:10.1002/bapi.201710036.

EN 16147. 2017. "Heat Pumps with Electrically Driven Compressors - Testing, Performance Rating and Requirements for Marking of Domestic Hot Water Units."

Feist, W, and J Schnieders. 2009. "Energy Efficiency - a Key to Sustainable Housing." Eur. Phys. J. Special Topics 176. EDP Sciences Springer-Verlag: 141153. doi:10.1140/epjst/e2009-01154-y.

Feist, Wolfgang. 1998. "PHPP - Passive House Planning Package." Passive House Institute. http://passiv.de/en/04_phpp/04_phpp.htm.

ibkinfo.at. "Wohnbauprojekt Campagneareal." https://www.ibkinfo.at/campagneareal2842.

iPHA. "Passive House Certification Criteria." https://passivehouseinternational.org/index.php?page_id=150\&level1_ $\mathrm{id}=78$.

MathWorks. $2016 . \quad$ "Matlab 2016b." https://de.mathworks.com/products/matlab.html.

Nussbaumer, Thomas, Stefan Thalmann, Andres Jenni, and Joachim Ködel. 2017. Planungshandbuch Fernwärme.

Ochs, Fabian. 2018. "Primary Energy Based Evaluation of Heat Pumps in District Heating Systems with Multi-Functional Thermal Energy Stores." In Solar District Heating Conference SDH 2018. Graz, Austria. www.solar-district-heating.eu.

Ochs, Fabian, and Georgios Dermentzis. 2018. "Evaluation of Efficiency and Renewable Energy Measures Considering the Future Energy Mix." In 7th International Building Physics Conference IBPC2018, 23-26 September. New York, USA.

Ochs, Fabian, Georgios Dermentzis, and Wolfgang Feist. 2014. "Minimization of the Residual Energy Demand of Multi-Storey Passive Houses Energetic and Economic Analysis of Solar Thermal and PV in Combination with a Heat Pump." Energy Procedia 48: 1124-1133. doi:10.1016/j.egypro.2014.02.127.

Österreichisches Institut für Bautechnik. 2015. "OIBRichtlinie 6. Energieeinsparung Und Wärmeschutz."

Siegele, Dietmar, Eleonora Leonardi, and Fabian Ochs. 2019. "A New MATLAB Simulink Toolbox for Dynamic Building Simulation with B.I.M. and Hardware in the Loop Compatibility." In Building Simulation. Rome, Italy: IBPSA.

Streicher, Wolfgang. 2019. Ermittlung Des Primärenergiemix Für Das FW Verbundnetz Der TIGAS Für 2017 Und Weiteren Ausbau (Internal Report). Innsbruck.

Truong, Nguyen Le, and Leif Gustavsson. 2019. "Costs and Primary Energy Use of Heating New Residential Areas with District Heat or Electric Heat Pumps." Energy Procedia 158 (2018). Elsevier B.V.: 2031-2038. doi:10.1016/j.egypro.2019.01.469.

Vaillant Rebollar, Julio Efrain, Eline Himpe, Jelle Laverge, and Arnold Janssens. 2017. "Sensitivity Analysis of Heat Losses in Collective Heat Distribution Systems Using an Improved Method of EPBD Calculations." Energy 140 (December). Elsevier Ltd: 850-860. doi:10.1016/j.energy.2017.08.021.

Wang, Zhikun. 2018. "Heat Pumps with District Heating for the UK's Domestic Heating: Individual versus District Level." Energy Procedia 149 (September). Elsevier B.V.: 354-362. doi:10.1016/j.egypro.2018.08.199. 